\title{
Untangling spatial and temporal variation in abundances of estuarine fish sampled with multi-mesh gillnets
}

\author{
D. Rotherham ${ }^{1, *}$, M. G. Chapman ${ }^{2}$, A. J. Underwood ${ }^{2}$, C. A. Gray ${ }^{1}$, D. D. Johnson ${ }^{1}$ \\ ${ }^{1}$ Industry and Investment NSW, Cronulla Fisheries Research Centre of Excellence, PO Box 21, Cronulla, \\ New South Wales 2230, Australia \\ ${ }^{2}$ Centre for Research on Ecological Impacts of Coastal Cities, School of Biological Sciences A11, University of Sydney, \\ New South Wales 2006, Australia
}

\begin{abstract}
Variability at small temporal scales can confound comparisons over longer periods of time but has often been ignored in studies of marine organisms. To determine appropriate methods for sampling fish at multiple temporal scales, we used hierarchical sampling to test hypotheses about temporal and spatial variation of individual species and assemblages of fish sampled with multi-mesh gillnets in shallow and deep habitats of a coastal lake in New South Wales, Australia. The design included temporal scales of $1 \mathrm{wk}, 1$ and 3 mo and spatial scales of sites (separated by $1 \mathrm{~km}$ ) and zones (separated by several $\mathrm{km}$ ). Patterns of temporal variation in univariate and multivariate analyses were complex and inconsistent across the different spatial scales and between habitats. The only general pattern was that spatial variance among replicate gillnet samples in each site was larger than variance at any of the temporal scales examined. Potential mechanisms explaining the observed patterns are likely to be complex and these are considered along with the implications for sampling assemblages of fish. A lack of generality in patterns of temporal variance reinforces the need for pilot studies to identify relevant scales of variation before commencing large-scale, long-term studies of any organism.
\end{abstract}

KEY WORDS: Estuaries · Fish assemblages • Hierarchical experimental design • Patchiness • Temporal variability · Variance

\section{INTRODUCTION}

Assemblages of organisms in terrestrial and aquatic environments vary naturally and inconsistently in space and time owing to a range of biotic and abiotic factors and their interactions (Botkin 1990, Thrush 1991, Levin 1992). Understanding such variability is a logical first step in forming hypotheses about processes affecting organisms (Wiens 1989, Underwood et al. 2000, Benedetti-Cecchi 2003). Similarly, identifying appropriate spatial and temporal scales of sampling is necessary for rigorous design and analysis of ecological experiments (Hewitt et al. 1997, Underwood et al. 2000), 'monitoring' programmes (Schroeter et al. 1993,
Thrush et al. 1994) and studies of environmental impacts (Andrew \& Mapstone 1987, Osenberg et al. 1994, Underwood 1997).

Hierarchical designs of sampling are effective for unravelling complex spatial and temporal patterns of distribution and abundance of plants and animals (Green 1979, Underwood \& Chapman 1996, Underwood 1997, McQuaid \& Lawrie 2005). They have the additional benefit of providing independent measures of variances for different nested spatial scales (Morrisey et al. 1992a, Underwood \& Chapman 1996, 1998). These designs are used in cost-benefit analyses, which can be used to optimise subsequent designs of sampling (Underwood 1997). 
Many studies have examined scales of variation at a hierarchy of different spatial scales (in soft sediment, e.g. Morrisey et al. 1992a, Moore \& Fairweather 2006, Chapman et al. 2010; on subtidal reefs, e.g. Fraschetti et al. 2001, Ellingsen \& Gray 2002, Anderson et al. 2005; on intertidal rocky shores, e.g. Underwood \& Chapman 1996, 1998, Benedetti-Cecchi 2001). Most studies on temporal variation, in contrast, have examined patterns at few and generally large scales, such as between seasons or years (e.g. Underwood 1984a, Hill \& Hawkins 1991, Lively et al. 1993, Williams 1993 among many others). Relatively few have measured variation in abundance of organisms at temporal scales within a season (e.g. Morrisey et al. 1992b, Olabarria \& Chapman 2002), or have simultaneously examined multiple temporal and spatial scales of variation (e.g. Kennelly \& Underwood 1992, Aberg \& Pavia 1997, Underwood \& Chapman 1998). Thus, while many researchers have recognised the problems of confounding in space (Hurlbert 1984), much less attention has been paid to avoiding equivalent problems of confounding in time (Stewart-Oaten et al. 1986, Underwood 1991, 1994).

Most studies examining spatial and temporal patterns of variation have focused on invertebrates or micro-algae (see references above). Whether the smallscale patchiness in time and space frequently observed for benthic assemblages is typical for organisms in other environments, particularly larger, more mobile organisms, is unclear. For example, fish are an important component of many aquatic ecosystems, but few studies have measured their variation at multiple temporal scales (e.g. Ferrell et al. 1993, Thompson \& Mapstone 2002). Further, patterns of variation among different scales are often inconsistent among studies of fish, although patchiness at small spatial or temporal scales has been observed for assemblages of fish on reefs (Thompson \& Mapstone 2002, Anderson \& Millar 2004) and in estuaries (Gray et al. 2009). Studies in other estuaries have, however, shown large and inconsistent variation in assemblages of fish from small to large spatial or temporal scales (Ferrell et al. 1993, Miller \& Skilleter 2006).

In estuaries of New South Wales (NSW), Australia, much research has focused on assemblages of small fish in shallow habitats, such as seagrass beds and bare substrata (e.g. Ferrell \& Bell 1991, Gray et al. 1996, Jones \& West 2005). By comparison, fewer studies have examined patterns of abundance in assemblages containing larger, more mobile species of fish, including those that are important in commercial and recreational fisheries (e.g. Pollard 1994). Also, catch rates derived from fishery-dependent sources often are not reliable indicators of abundance (e.g. Walters \& Maguire 1996).
In an earlier study (Gray et al. 2009), we examined spatial scales of variation of assemblages of fish sampled with multi-mesh gillnets in shallow and deep habitats of coastal lakes. That work was part of the development of scientific tools for sampling a wide range of species and sizes of estuarine fish. A consistent result was that variation in abundance was largest at the smallest spatial scale investigated (i.e. among replicate nets placed 50 to $100 \mathrm{~m}$ apart). Variation was also generally larger between sites (1 km apart) than among zones (several $\mathrm{km}$ apart) within an estuary. Whether the spatial patterns of variation observed in that particular study are consistent through time, or, indeed, which temporal scales would need to be included in future sampling programmes was unknown.

Many studies examining temporal changes in populations and assemblages of fish have sampled seasonally (e.g. Horn 1980, Hyndes et al. 1999, Desmond et al. 2002, Ikejima et al. 2003, Jones \& West 2005). Comparisons among seasons are, however, potentially confounded by variation at smaller time-scales (Morrisey et al. 1992b). When sampling is done only once in each season, a comparison of seasons can only be interpreted sensibly if the assumption that any single time of sampling is representative of other times in the same season is made. Without replicated times of sampling within each season, this cannot be ascertained. Differences interpreted to be seasonal may just represent temporal differences within each season. This is an important matter that is often overlooked in the design and interpretation of sampling. For example, movements of fish in response to changes in patterns of tides (Morrison et al. 2002), moonlight (Blaber \& Blaber 1980), foraging (Thompson \& Mapstone 2002), or interactions among these and other factors, may cause patchiness in abundance at scales of days, weeks or months (e.g. Thompson \& Mapstone 2002, Miller \& Skilleter 2006).

The aims of the present study were, therefore, to examine the extent to which small-scale temporal variation may confound seasonal and spatial comparisons of abundances of fish sampled with multi-mesh gillnets (sensu Morrisey et al. 1992b) and to identify appropriate scales of sampling for future studies. This study was not designed to offer any interpretations of temporal patterns of abundances of fish, nor to determine how the biology and ecology of each species might influence these. Its purpose was to determine what sorts of temporal sampling are necessary to be able to describe abundance in different places at different times. We therefore measured variability in populations and assemblages of fish at a hierarchy of temporal scales in shallow and deep strata (habitats) of a coastal estuary in NSW. Sampling included the 2 spatial scales to test the generality of patterns of temporal variance and to investigate any interactions between patterns in space and 
time. Specifically, we tested the hypotheses that (1) there would be temporal variation at the largest scale of $3 \mathrm{mo}$, which is a typical sampling interval used to test seasonal variation (see above), but not at smaller scales within 3 mo (i.e. weeks and months), (2) most spatial variation would be at small scales (i.e. among replicates and between sites) consistently through time as observed for a single time of sampling in Gray et al. (2009), and (3) patterns of variation would be consistent among species and between habitats.

\section{MATERIALS AND METHODS}

Sampling design and methods. Sampling was done in St Georges Basin NSW, a relatively shallow (mean depth of about $2 \mathrm{~m})$, micro-tidal $(<0.5 \mathrm{~m})$ and wellmixed coastal lake with a surface area of about $44 \mathrm{~km}^{2}$ (Roy et al. 2001). The sampling design included 2 habitats, shallow $(\mathrm{S},<2 \mathrm{~m})$ and deep $(\mathrm{D},>4 \mathrm{~m})$ strata, and 2 spatial scales, 2 sites (1 km apart) nested in each of 2 zones ( $\mathrm{Z}, \sim 3$ to $8 \mathrm{~km}$ apart). Although we did not quantify differences between the physical structure of shallow and deep habitats, previous work has shown that shallow areas of St Georges Basin are often characterised by patchy distributions of seagrasses and bare sediment (Creese et al. 2009), meaning further stratification of sampling with gillnets by the type of habitat within shallow and deep strata (e.g. bare vs. seagrass) was impractical. In deeper areas of the lake $(>4 \mathrm{~m})$, seagrasses are generally restricted to the fringe of the central mud basin (Roy et al. 2001, Creese et al. 2009). So, most of our sampling in deep habitats was probably done over predominantly unvegetated sediments.

The choice of spatial scales was dependent on our hypothesis that patterns of spatial variation observed in our previous study (i.e. Gray et al. 2009) would be consistent through time. In that previous study, however, the choice of spatial scales was arbitrary because we did not have other information. This is a common issue in studies of spatial scales in the absence of complete maps of distributions (when natural scales might be available) or, as here, with continuous sampling across all possible scales being impractical.

One night was necessary to sample both habitats in a site. Each site was sampled for 2 consecutive weeks in each of 2 consecutive months in each of 2 consecutive 'seasons' in 2005: winter (July to August) and summer (October to November). These seasons were chosen arbitrarily because there was no clear evidence to suggest that patterns of temporal variation would be different for assemblages of fish within or between other seasons (i.e. summer and autumn). We could not measure variation at shorter time-scales (i.e. among nights) because 4 nights were needed to sample the 4 sites.
During each night, 6 replicate multi-mesh gillnets separated by 50 to $100 \mathrm{~m}$ were sampled in each habitat at a single site chosen at random. The gillnets were bottomset, soaked for $1 \mathrm{~h}$ and then retrieved (Rotherham et al. 2006). Catches in each net were identified and counted; economically-important species of fish were measured for fork-length (FL) to the nearest $0.5 \mathrm{~cm}$.

Each multi-mesh gillnet consisted of seven $20 \mathrm{~m}$ panels of different sizes of stretched mesh $(36,44,54$, $63,76,89$ and $102 \mathrm{~mm}$ ), connected together in a random order. Adjacent panels were separated by $5 \mathrm{~m}$ of rope to minimise potential effects of the smaller-mesh panels 'leading' larger fish to adjacent panels. The 36 and $44 \mathrm{~mm}$ panels were made from monofilament netting with twine diameter of $0.15 \mathrm{~mm}$; the remaining panels had multifilament netting with a twine diameter of $0.4 \mathrm{~mm}$. All panels were $2 \mathrm{~m}$ deep and had a hanging ratio of $\mathrm{E}=0.5$.

Analyses of data. For each species present in at least $25 \%$ of samples in each habitat (across all times of sampling), spatio-temporal variation in abundance was estimated using ANOVA on untransformed data. Data were not transformed even when variances were heterogeneous because it was important to compare results among species in a similar scale (Olabarria \& Chapman 2002). In addition, the components of variation needed to be extracted from the true variances, and ANOVA tests are relatively robust to heterogeneous variances in large, balanced designs, as here (Underwood 1997).

Initial analyses of the full 5-factor model separately for each habitat (i.e. 3 nested temporal scales orthogonal to zones and sites) revealed significant temporalspatial interactions at small scales (Table 1). To estimate temporal variances independently of interactions with spatial patterns, the 3 temporal scales were analysed separately for each site and habitat using nested ANOVAs with all factors included as random effects. The components of variation for each temporal scale were then extracted (Underwood 1997), correcting for negative values, where present, according to Fletcher \& Underwood (2002). There were thus 4 independent estimates of each temporal component, one from each site. For each site, analyses were done for species found in at least $25 \%$ of samples at that site, which increased the number of species analysed compared to the full 5-factor model. The components of variation for each temporal scale were then averaged for each species over the appropriate number of sites (between 1 and 4). Because there were so many spatial-temporal interactions in the univariate analyses, multivariate analyses would clearly be similarly interactive. Therefore, PERMANOVA (Anderson 2001) was done on Bray-Curtis dissimilarities calculated from untransformed data, and multivariate components of vari- 
ation (i.e. for all species, irrespective of their frequencies of occurrence) were calculated for each temporal scale exactly as was done for the univariate analyses.

To test the consistency of spatial patterns of variance through time, similar analyses of frequently occurring species (found in $\geq 25 \%$ of samples) and multivariate assemblages were done, as described above. Two factors (zones and sites) were analysed for each time of sampling and habitat separately, potentially giving 8 independent estimates of variance for sites and zones. These were then averaged over the appropriate number of sampling times.

\section{RESULTS}

\section{Spatio-temporal variability in abundances}

Twelve species in the shallow habitat and 10 species in the deep habitat were sufficiently widespread (i.e. caught in $\geq 25 \%$ of samples) to be analysed using the full model (Table 1). Because all factors were random, there were no tests for the effects of 3 mo (3M), 1 mo (1M) nested in $3 \mathrm{M}$ (i.e. $1 \mathrm{M}(3 \mathrm{M}))$ and Zones (Z), nor for the interactions $Z \times 3 M$ and $Z \times 1 M(3 M)$, unless other terms in the analyses could be eliminated or pooled (Underwood 1997). Where there were significant interactions, the effects of main factors were not interpreted (Underwood 1997).

Of 12 species analysed for the shallow habitat and 10 analysed for the deep habitat, only 4 species in each habitat showed no significant differences in time or space (Table 1). Of the remaining species, 5 out of 12 in the shallow habitat and 4 out of 10 in the deep habitat showed significant space-time interactions at the smallest scales (i.e. $\mathrm{S}(\mathrm{Z}) \times \mathrm{W}(1 \mathrm{M}(3 \mathrm{M})$ ); Table 1). Thus, for many species, temporal changes in mean abundances were not the same from site to site (illustrated in Fig. 1 for Sillago ciliata in the shallow and deep habitats). Only $S$. ciliata and Gerres subfasciatus showed these smallscale interactions in shallow and deep habitats. In contrast, Girella tricuspidata Pomatomus saltatrix and $S$. maculata gave significant $\mathrm{S}(\mathrm{Z}) \times \mathrm{W}(1 \mathrm{M}(3 \mathrm{M}))$ interactions in one, but not the other habitat (illustrated in Fig. 2 for G. tricuspidata).

A significant interaction between small temporal but larger spatial scales (i.e. $\mathrm{Z} \times$ $\mathrm{W}(1 \mathrm{M}(3 \mathrm{M})))$ was detected in 2 species in the shallow habitat (Girella tricuspidata and Mugil cephalus) and 1 species in the deep habitat (i.e. Platycephalus fuscus; Fig. 3). Significant interactions between either spatial scale and larger temporal scales were seldom found. They were $\mathrm{S}(\mathrm{Z}) \times 1 \mathrm{M}(3 \mathrm{M})$ for $P$. fuscus in the deep areas (Fig. 3) and $\mathrm{S}(\mathrm{Z}) \times 3 \mathrm{M}$ for $M$. cephalus in the deep areas (Table 1). Significant differences at the scales of weeks (i.e. W(1M(3M))) and sites (i.e. $\mathrm{S}(\mathrm{Z})$ ) were detected in only one analysis ( $P$. fuscus, shallow; Table 1, Fig. 3).

\section{Components of temporal variation}

For 21 of the 29 analyses on individual species in either or both of the habitats, components of variation were negative at one or more scales (examples shown in Table 2a), indicating that these terms probably had zero variance and should be taken out of the analyses and the data re-analysed (Fletcher \& Underwood 2002). Only 6 of these analyses had negative components at the largest scale of 3 mo (e.g. Sillago ciliata

Table 1. Summary of significant results of 5-factor ANOVAs used to test for differences in mean abundances of individual species of fish at different temporal and spatial scales, separately for shallow and deep habitats. The 3 temporal scales were 3 mo (3M), 1 mo (1M) nested in 3 mo and weeks (W) nested in 1 mo nested in $3 \mathrm{mo}$, which were orthogonal to zones (Z) and sites (S) nested in zones. Non-significant $(p>0.25)$ interaction terms were pooled, where possible, to increase the number of degrees of freedom

\begin{tabular}{|lcccc|}
\hline Species & $\begin{array}{c}\text { Significant terms in } \\
\text { ANOVA }\end{array}$ & df & $F$ & $\mathrm{p}$ \\
& & & \\
\hline (a) Shallow habitat & & & & \\
Acanthopagrus australis & $\mathrm{None}$ & & & \\
Gerres subfasciatus & $\mathrm{S}(\mathrm{Z}) \times \mathrm{W}(1 \mathrm{M}(3 \mathrm{M}))$ & 8,160 & 3.36 & $<0.01$ \\
Girella tricuspidata & $\mathrm{Z} \times \mathrm{W}(1 \mathrm{M}(3 \mathrm{M}))$ & 4,168 & 2.83 & $<0.05$ \\
Liza argentea & $\mathrm{S}(\mathrm{Z}) \times \mathrm{W}(1 \mathrm{M}(3 \mathrm{M}))$ & 8,160 & 3.13 & $<0.01$ \\
Mugil cephalus & $\mathrm{Z} \times \mathrm{W}(1 \mathrm{M}(3 \mathrm{M}))$ & 4,168 & 6.44 & $<0.01$ \\
Myxus elongatus & $\mathrm{S}(\mathrm{Z}) \times \mathrm{W}(1 \mathrm{M}(3 \mathrm{M}))$ & 8,160 & 2.26 & $<0.05$ \\
Platycephalus fuscus & $\mathrm{W}(1 \mathrm{M}(3 \mathrm{M}))$ & 4,178 & 4.34 & $<0.01$ \\
& $\mathrm{~S}(\mathrm{Z})$ & 2,178 & 9.74 & $<0.001$ \\
Pomatomus saltatrix & $\mathrm{S}(\mathrm{Z}) \times \mathrm{W}(1 \mathrm{M}(3 \mathrm{M}))$ & 8,160 & 5.27 & $<0.001$ \\
Pseudocaranx dentex & $\mathrm{None}$ & & & \\
Rhabdosargus sarba & $\mathrm{None}$ & & & \\
Sillago ciliata & $\mathrm{S}(\mathrm{Z}) \times \mathrm{W}(1 \mathrm{M}(3 \mathrm{M}))$ & 8,160 & 2.14 & $<0.05$ \\
Sillago maculata & $\mathrm{None}$ & & & \\
& & & & \\
(b) Deep habitat & $\mathrm{None}$ & & & \\
Acanthopagrus australis & $\mathrm{S}(\mathrm{Z}) \times \mathrm{W}(1 \mathrm{M}(3 \mathrm{M}))$ & 8,160 & 2.41 & $<0.05$ \\
Gerres subfasciatus & $\mathrm{S}(\mathrm{Z}) \times \mathrm{W}(1 \mathrm{M}(3 \mathrm{M}))$ & 8,160 & 2.21 & $<0.05$ \\
Girella tricuspidata & $\mathrm{S}(\mathrm{Z}) \times 3 \mathrm{M}$ & 2,16 & 7.20 & $<0.01$ \\
Mugil cephalus & $\mathrm{S}(\mathrm{Z}) \times 1 \mathrm{M}(3 \mathrm{M})$ & 4,168 & 4.87 & $<0.01$ \\
Platycephalus fuscus & $\mathrm{Z} \times \mathrm{W}(1 \mathrm{M}(3 \mathrm{M}))$ & 4,168 & 3.03 & $<0.05$ \\
& $\mathrm{None}$ & & & \\
Pomatomus saltatrix & $\mathrm{None}$ & & & \\
Pseudocaranx dentex & $\mathrm{None}$ & & & \\
Rhabdosargus sarba & $\mathrm{S}(\mathrm{Z}) \times \mathrm{W}(1 \mathrm{M}(3 \mathrm{M}))$ & 8,160 & 7.40 & $<0.001$ \\
Sillago ciliata & $\mathrm{S}(\mathrm{Z}) \times \mathrm{W}(1 \mathrm{M}(3 \mathrm{M}))$ & 8,160 & 2.70 & $<0.01$ \\
Sillago maculata & & & & \\
\hline
\end{tabular}


a) Shallow

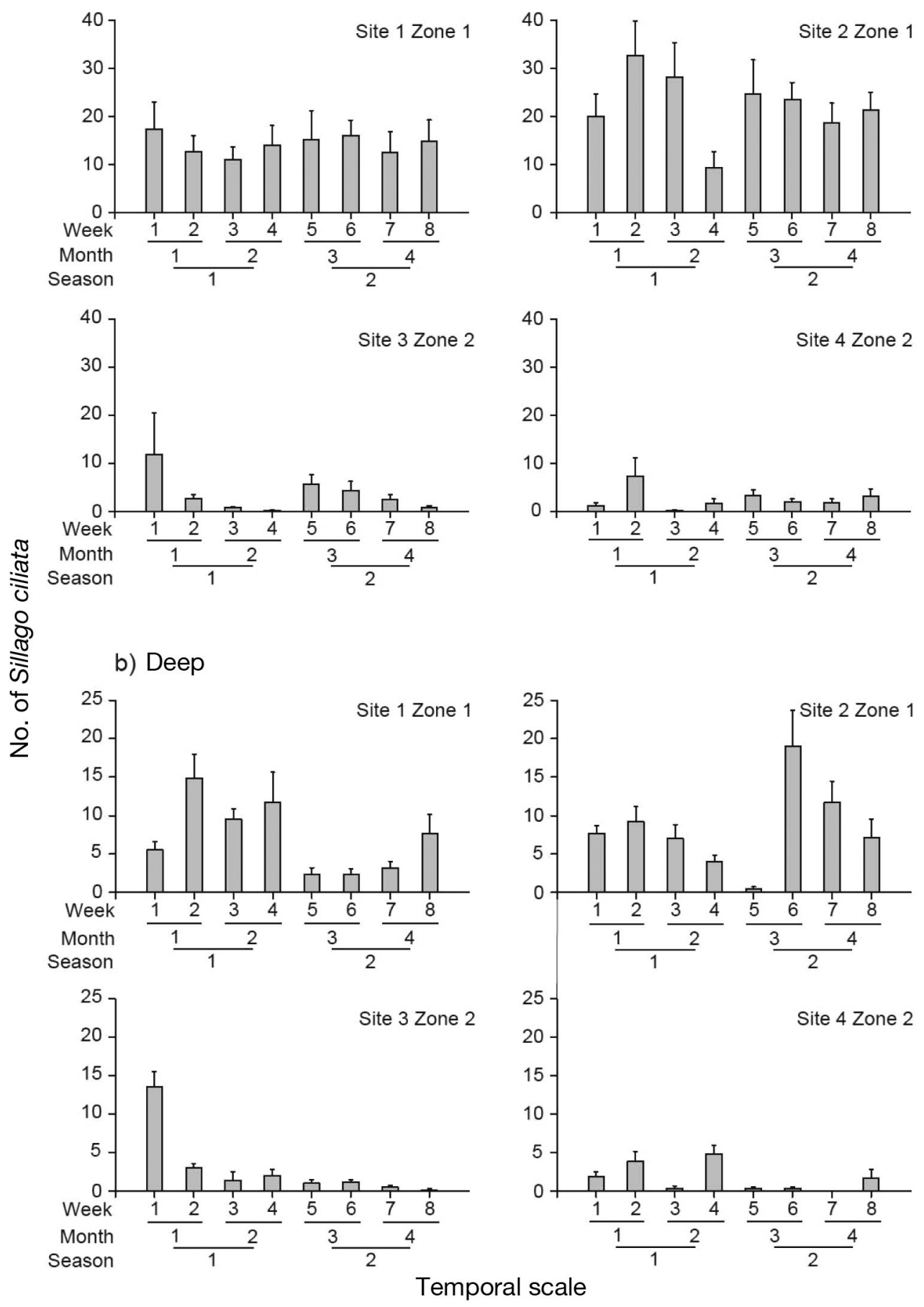

Fig. 1. Sillago ciliata. Mean numbers $\left(+\mathrm{SE}_{i} \mathrm{n}=6\right)$ of $S$. ciliata sampled with multi-mesh gillnets at a hierarchy of temporal scales at each site and zone in the (a) shallow and (b) deep habitats of St Georges Basin

in Table 2a). The data were thus re-analysed, collapsing the weeks and months into 4 'times' of sampling within 3 mo (Table 2b), because neither weeks nor months contributed to any variances. Many of the negative components disappeared; only 10 of the analyses still had negative values when averaged over the relevant samples (Table 3). For these, we corrected the mean square estimates in the original analyses, by removing times, $3 \mathrm{mo}$, or both (as described in Fletcher \& Underwood 2002). The components of variation were then averaged again over the relevant number of sites. 
a) Shallow
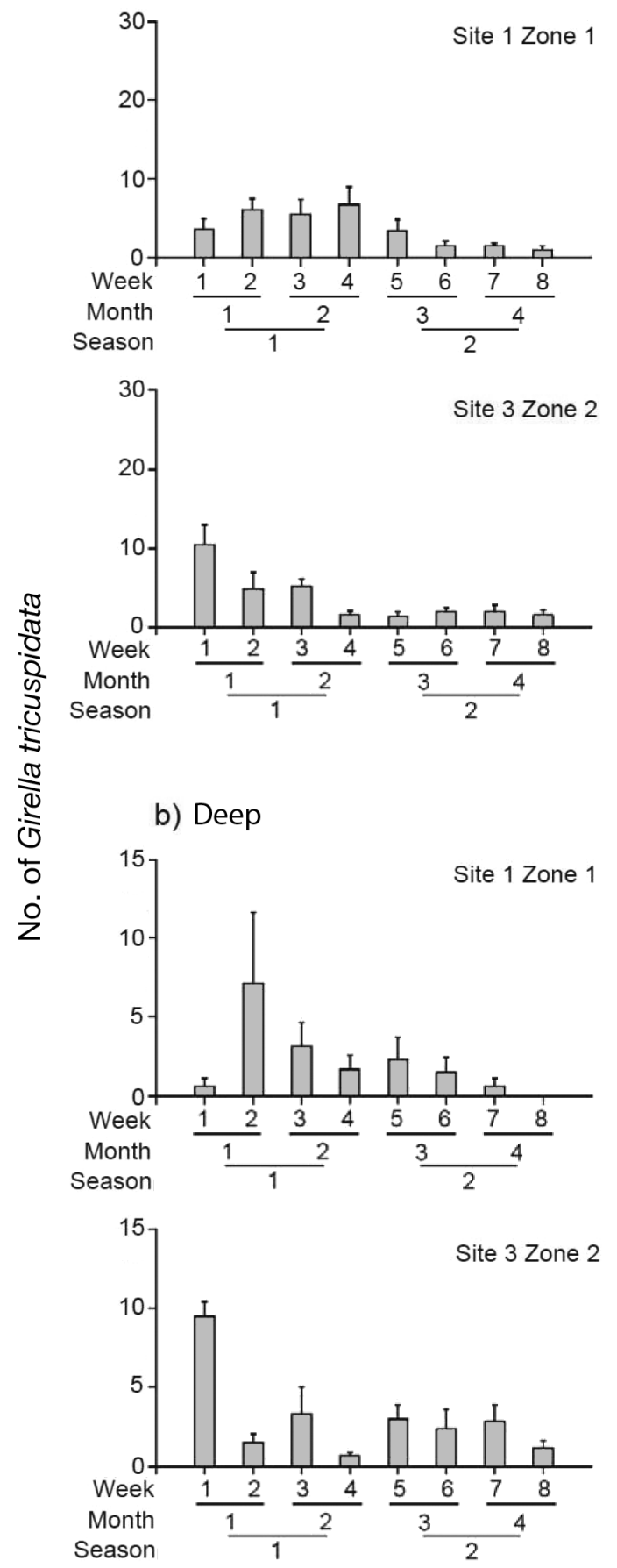
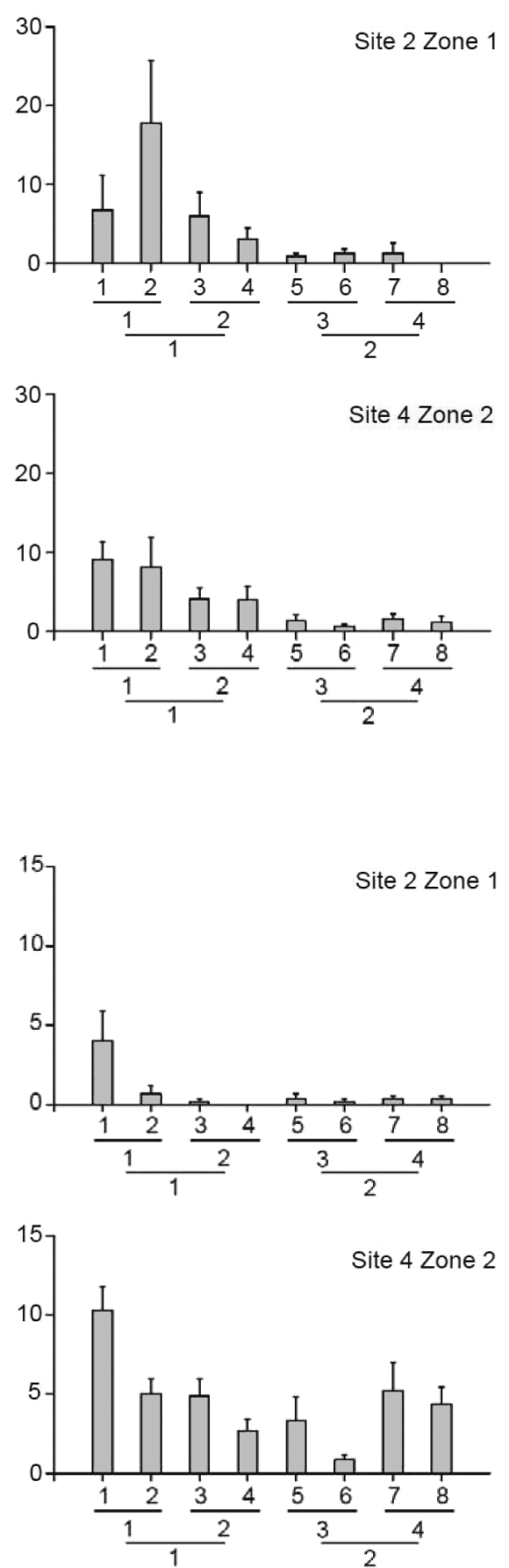

Temporal scale

Fig. 2. Girella tricuspidata. Mean numbers $\left(+\mathrm{SE}_{;} \mathrm{n}=6\right)$ of G. tricuspidata sampled with multi-mesh gillnets at a hierarchy of temporal scales at each site and zone in the (a) shallow and (b) deep habitats of St Georges Basin

For sampling multiple species, measuring how much variability is associated with any particular spatial or temporal scale is necessary. This is made difficult where different species have different residual variance (i.e. variation from net to net). We therefore decided to make comparable estimates by normalizing the variance components (each component was divided by that species' residual variation). This assessed how much additional variation would be added by sampling at additional temporal scales (i.e. by adding another 3 mo 
a) Shallow

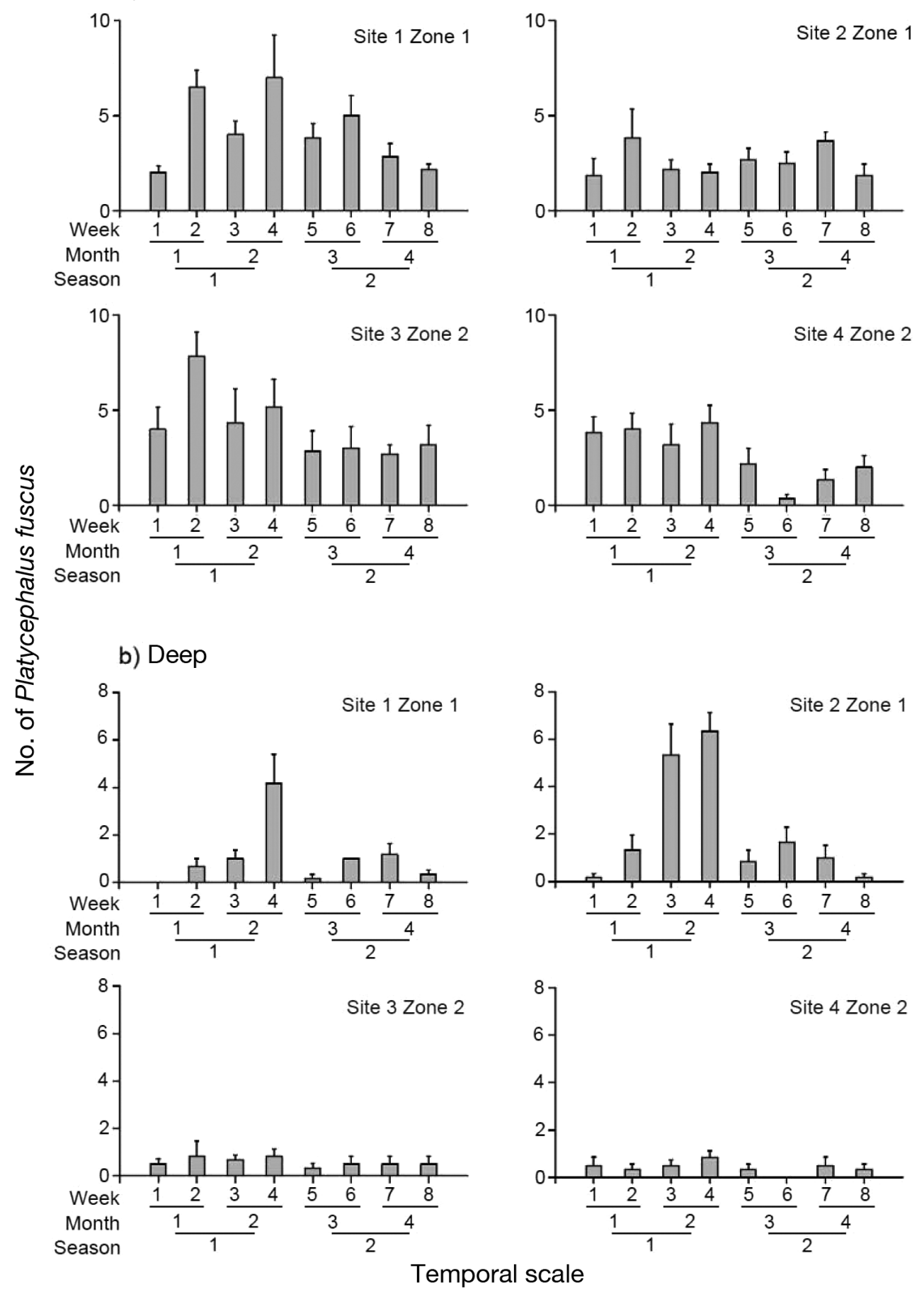

Fig. 3. Platycephalus fuscus. Mean numbers ( $\mathrm{SE} ; \mathrm{n}=6)$ of $P$. fuscus sampled with multi-mesh gillnets at a hierarchy of temporal scales at each site and zone in the (a) shallow and (b) deep habitats of St Georges Basin

period or time, rather than adding more replicate gillnets). For some species, times within a 3 mo period added most additional variation (e.g. Liza argentea, shallow). For others, differences among 3 mo periods added most variation (e.g. Mugil cephalus, shallow;
Pagrus auratus, deep). The latter pattern was consistent among species in the shallow, but not in the deep sites. Similarly, patterns of temporal variance were often inconsistent for the same species between depths (i.e. L. argentea, Pseudocaranx dentex, Platycephalus 
Table 2. Examples of different patterns in temporal components of variance for species of fish averaged over different sites from ANOVAs of (a) 3 levels of the temporal hierarchy: 3 mo (3M), 1 mo (1M) and weeks (W), and (b) after the scales of weeks and months were collapsed into times $(\mathrm{T})$ of sampling within a 3-mo period. S: shallow habitats; D: deep habitats; Res: residual variance

\begin{tabular}{|lrrccc|}
\hline & & df & $\begin{array}{c}\text { Sillago } \\
\text { ciliata } \\
\text { (S) }\end{array}$ & $\begin{array}{c}\text { Acanthopagrus } \\
\text { australis } \\
\text { (D) }\end{array}$ & $\begin{array}{c}\text { Liza } \\
\text { argentea } \\
\text { (D) }\end{array}$ \\
\hline (a) & 3M & 1 & -4.6 & 1.4 & 2.5 \\
& 1M & 2 & -1.3 & -0.4 & 1.2 \\
& W & 4 & 6.7 & 0.5 & -1.1 \\
& Res & 40 & 90.1 & 4.4 & 15.4 \\
(b) & 3M & 1 & 0 & 1.2 & 2.9 \\
& T & 6 & 6.5 & 0.2 & 0.2 \\
& Res & 40 & 87.4 & 4.4 & 15 \\
\hline
\end{tabular}

fuscus, Sillago maculata, Gerres subfasciatus). The only consistent pattern between habitats, among species and between the results from the univariate and multivariate analyses was that the residual variation, which is a spatial component, was greater than any temporal scale examined (Table 3 ). Thus, the amount of variation added by sampling at additional times or 3 mo periods was small compared to sampling additional gillnets at small spatial scales (i.e. replicate nets separated by 50 to $100 \mathrm{~m})$.

\section{Components of spatial variation}

Most spatial variation was at the smallest scale of replicate nets separated by 50 to $100 \mathrm{~m}$ (Table 4). This was consistent between habitats in univariate and multivariate analyses. The magnitude of the contribution of zones or sites to spatial variance was inconsistent among species and between habitats for the individual species. In the shallow habitat, components of variation were larger at the scale of sites than at the scale of zones for 7 out of 14 species, but larger for zones than for sites for 6 out of 14 species. For one species (Pelates sexlineatus), variation at the scales of sites and zones was equivalent (i.e. zero). In the deep habitat, in contrast, there was more variation at the scale of zones than sites for 10 of the 12 species analysed. For the multivariate data, in both habitats, variation among zones was larger than that among sites.

\section{DISCUSSION}

Patterns of spatial and temporal variation in this study were inconsistent and complex. Many analyses of individual species of fish from the shallow and deep habitats detected significant spatio-temporal interactions at small scales (i.e. between the scale of sites only $1 \mathrm{~km}$ apart and consecutive weeks). Patterns of change measured in one site could not represent the changes occurring in another nearby site. A second important finding was that, in any site (thus, eliminating spatiotemporal interactions and providing independent estimates of variance for each temporal scale), there were no general patterns in the relative magnitudes of the components of variation among the different temporal scales for individual species between habitats, nor between these and changes in the assemblage (as shown by the multivariate analyses).

Fish are not unique in showing complex and inconsistent patterns of abundance through time. This has, as a good comparative example, been a major focus of attention in sampling benthic animals in muddy and on rocky substrata. Although similar, small-scale interactions between time and space have been observed for such benthic assemblages (Thrush et al. 1996, Underwood \& Chapman 1998, Olabarria \& Chapman 2002), many studies have also shown that the largest sources of spatial and temporal variability in abundances of such organisms are often at the smallest scales (Morrisey et al. 1992a,b, Underwood \& Chapman 1996, 1998; reviewed by Fraschetti et al. 2005). Such patterns may be related to a number of biotic (e.g. predation, Connell 1975; competition, Jernakoff 1985; availability of food, Underwood 1984b) and abiotic variables (e.g. topographic complexity, Chapman \& Underwood 1994; natural disturbances, Underwood 1999). These features of the ecology of the organisms vary and interact at small spatial and temporal scales.

Our mensurative study cannot provide evidence for any processes causing the observed patterns in abundance of species of fish (Underwood et al. 2000). Nevertheless, a lack of any consistent patterns of temporal variance indicates that assemblages of fish are likely to be affected by a complex set of processes, which operate at a range of different scales in time (not just at the smallest scales as suggested for benthic assemblages) and differently among sites and between habitats. In contrast to the benthic invertebrates studied elsewhere (see references in the previous paragraph), many of the species of fish sampled in the present study are mobile, fast-moving organisms. The mobility of fish over small to large temporal and spatial scales, together with interactions among other small-scale factors (e.g. predation and competition), are likely to contribute to the complex patterns of change that were observed. Processes of immigration/emigration of microgastropods (owing to potentially greater dispersal than other benthic invertebrates) and interactions with processes at small scales have been hypothesised to explain similar, inconsistent patterns of variation over scales of 
Table 3. Components of temporal variance for species of fish found in at least $25 \%$ of samples and for multivariate assemblages averaged over different sites in shallow and deep habitats of St Georges Basin. na: no analysis; 3M: 3 mo; T: times within 3 mo; Res: residual variance

\begin{tabular}{|lcccccr|}
\hline \multirow{2}{*}{ Species } & \multicolumn{3}{c}{ Shallow } & & \multicolumn{3}{c|}{ Deep } \\
& 3M & T & Res & $3 \mathrm{M}$ & $\mathrm{T}$ & Res \\
\hline Acanthopagrus australis & 0.2 & 0.1 & 2.6 & 1.2 & 0.2 & 4.4 \\
Chelidonichthys kumu & na & na & na & 0.1 & 0 & 1.1 \\
Gerres subfasciatus & 35.7 & 14.3 & 43.2 & 0.7 & 6.3 & 18.6 \\
Girella tricuspidata & 11.9 & 3.7 & 27.7 & 0.2 & 3.9 & 9.4 \\
Herklotsichthys castelnaui & 64.5 & 44.5 & 346 & 24.4 & 7.4 & 36.2 \\
Liza argentea & 0.4 & 17.8 & 32.9 & 2.9 & 0.2 & 15 \\
Meuschenia trachylepis & 16.1 & 0 & 45.7 & na & na & na \\
Mugil cephalus & 7.2 & 2.3 & 7.4 & 4.8 & 0.6 & 5.5 \\
Myxus elongatus & 3.7 & 1.9 & 13.3 & na & na & na \\
Pagrus auratus & na & na & na & 1.4 & 0 & 2.1 \\
Pelates sexlineatus & 0.7 & 0 & 32 & na & na & na \\
Platycephalus fuscus & 1.3 & 0.6 & 5.8 & 0.4 & 1.4 & 1.4 \\
Pomatomus saltatrix & 0 & 2.4 & 3.5 & 0.1 & 0.6 & 3.8 \\
Pseudocaranx dentex & 0 & 0.6 & 3.6 & 1 & 0.5 & 1.7 \\
Rhabdosargus sarba & 0.7 & 0.6 & 2.8 & 0.3 & 0.1 & 6.3 \\
Sillago ciliata & 0 & 6.5 & 87.4 & 5.1 & 12.7 & 17.4 \\
Sillago maculata & 0.6 & 0.2 & 2.1 & 0.2 & 0.8 & 2.4 \\
Multivariate & 603.4 & 248.1 & 1408.3 & 577 & 479 & 1560.9 \\
\hline
\end{tabular}

Table 4. Components of spatial variance for individual species of fish found in at least $25 \%$ of samples and for multivariate assemblages averaged over multiple times of sampling in shallow and deep habitats of St Georges Basin. na: no analysis; Z: zones; S: sites; Res: residual variance

\begin{tabular}{|lcrcrrr|}
\hline Species & \multicolumn{3}{c}{ Shallow } & & \multicolumn{3}{c|}{ Deep } \\
& $\mathrm{Z}$ & $\mathrm{S}$ & \multicolumn{1}{c}{ Res } & $\mathrm{Z}$ & $\mathrm{S}$ & Res \\
\hline Acanthopagrus australis & 0 & 0.2 & 3.1 & 0.9 & 0.7 & 4.4 \\
Gerres subfasciatus & 14.7 & 43.6 & 43.7 & 5.5 & 2.3 & 11.6 \\
Girella tricuspidata & 0.7 & 1.3 & 27.7 & 4.3 & 2 & 10.2 \\
Herklotsichthys castelnaui & 108.6 & 7.7 & 329.3 & 38 & 5.9 & 162.9 \\
Liza argentea & 17.1 & 10.4 & 29 & 2.9 & 0 & 3.1 \\
Mugil cephalus & 8.5 & 1.9 & 8.2 & 1.1 & 1.4 & 4.4 \\
Myxus elongatus & 9.3 & 1.1 & 13.3 & na & na & na \\
Pelates sexlineatus & 0 & 0 & 12 & na & na & na \\
Platycephalus fuscus & 0.3 & 1 & 5.7 & 3.4 & 1.5 & 2.5 \\
Pomatomus saltatrix & 0 & 0.9 & 3.2 & 0.9 & 0.1 & 4.2 \\
Pseudocaranx dentex & 0 & 2.5 & 5.6 & 1.4 & 1 & 3.2 \\
Rhabdosargus sarba & 0.5 & 0.6 & 3.9 & 0.3 & 0.2 & 8.5 \\
Sillago ciliata & 100.9 & 19.5 & 90.1 & 13.6 & 18.2 & 19.7 \\
Sillago maculata & 1.6 & 1.3 & 4.1 & 0.8 & 0 & 5.7 \\
Multivariate & 920.4 & 308.5 & 1408.3 & 731.1 & 422.3 & 1560.9 \\
\hline
\end{tabular}

iour. Similarly, such factors are likely to contribute to the inconsistent patterns of variation observed among species of fish in our study and differences in patterns between other studies examining short-term temporal variation of fish (e.g. tropical reef fish, Thompson \& Mapstone 2002; sub-tropical estuarine fish, Miller \& Skilleter 2006).

As predicted, some species in our study showed most variation at the largest scale of 3 mo consistently between habitats, perhaps as a result of seasonal spawning migrations (Potter et al. 1986, Hagan \& Able 2003, Katselis et al. 2007). Many other species were, however, more variable from time to time within a season, which may have been related to inter-specific differences in responses to factors acting at scales ranging from days to months (e.g. changes in moonlight, Blaber \& Blaber 1980; availability of food, Humphries \& Potter 1993; changes from spring to neap tides, Krumme et al. 2008). Although changes in tides are an important influence on distribution and abundance of some species of fish at small temporal scales (e.g. Gibson et al. 1996), they are unlikely to have made large contributions to the differences we found because St Georges Basin has a very small tidal range $(<0.5 \mathrm{~m})$.

In addition to the patterns above, there were intra-specific differences in patterns of temporal and spatial variance between shallow and deep habitats, which may indicate different processes acting in each habitat such as features of the habitat (e.g. physical structure, Hyndes et al. 2003, Horinouchi 2007) and interactions with ontogenetic factors (Eggold \& Motta 1992, Platell et al. 2006). Fish may move

weeks, months and 3 mo periods (Olabarria \& Chapman 2002). Despite the greater distances moved by individual fish, temporal patterns of mobile populations of fish and small snails show similar inconsistencies. Distances moved are not, of themselves, an important difference between these different assemblages.

Differences in patterns of temporal variation between fish and other invertebrates are likely to result not only from differences in scales of dispersal or movement but also from differences in life cycles, rates of reproduction (e.g. Desmond et al. 2002) and behav- between or among different habitats at different stages of their life history (e.g. Potter et al. 1990, Miller \& Skilleter 2006). The deep habitat often contained larger individuals of many species, which was consistent with our earlier study (Gray et al. 2009). Larger or older fish may forage over larger spatial scales than do smaller conspecifics (thus potentially explaining the larger variation at the scales of zones in the deep sites). Sexually immature or very old fish may not participate in seasonal spawning migrations. Factors such as changes in moonlight are also likely to have different 
effects on the behaviour and movements of predators and prey between deep and shallow sites (sensu Lowry et al. 2007). Thus, similar processes could act in different habitats but at different rates (Steele 1985).

Unlike the individual species, patterns of spatial and temporal variance of multivariate assemblages were consistent between deep and shallow habitats. Most temporal variance in assemblages of fish was, as predicted, at the scale of 3 mo periods. Spatial variation was larger between zones than between sites within zones. These results illustrate that patterns of assemblages do not necessarily reflect patterns of individual abundant or widespread species (sensu Chapman et al. 2010). This finding highlights the potential problem of selecting and focusing on few, so-called 'indicator' species in studies of environmental monitoring (e.g. Dale \& Beyeler 2001, Goodsell et al. 2009); patterns indicated by such species may not be representative of many other species in an assemblage, particularly those that are rare or uncommon.

One consistent feature of both the univariate and multivariate analyses was that many of the temporal components of variation were estimated to be negative. Negative estimates suggest that variability at a particular scale is less than would be expected from the variability observed at a smaller scale (Fletcher \& Underwood 2002). For many species and all analyses of multivariate assemblages, negative estimates of temporal components averaged out when mean variance was calculated across multiple sites, indicating that each temporal scale of variation added, on average, at least a small amount of variance to the overall patterns of temporal variation. Some of the persistent negative values reflect that some species were only found in 1 or 2 sites and therefore estimates of mean variance were not very reliable. For widespread or abundant species (i.e. those found in most sites), persistent negative estimates may indicate temporal non-independence among times of sampling (i.e. data may be positively or negatively correlated, see Underwood 1997). Nevertheless, data were likely to be independent because patterns of change from time to time in any site were inconsistent and unpredictable for many species (Figs. 1 to 3 ).

The residual variance, which estimated spatial variation among replicate nets in a site in a single night, was larger than variation at any of the temporal (or spatial) scales examined. This was the only general pattern among many species, between the univariate and multivariate analyses and between shallow and deep habitats. The schooling behaviour of many species likely explained much of the patchiness among replicate nets. Often, large numbers of a particular species were caught in 1 or 2 replicate nets within a site, but few or no individuals were caught in the other nets that were relatively close by (i.e. separated by 50 to $100 \mathrm{~m}$ ).
Patchiness at small spatial scales has also been observed for reef fishes and again may be explained by the fact that many species of fish are very mobile (Anderson \& Millar 2004). Movements of individual fish (or schools of fish) over short distances and periods of time may be random or related to the interaction of different factors at local scales (McClanahan et al. 2007). For example, small-scale physical or biogenic features of habitat can affect the foraging behaviour of fish by providing food or refuge from predators (Auster et al. 1995, Thrush et al. 2002). Such factors can also explain the patchy small-scale distribution of fishes in our study, because the sites sampled in St Georges Basin often contained a mosaic of patches of seagrass, macroalgae and bare sediment (West et al. 1985, Cummins et al. 2004) with patches of invertebrates such as sponges and ascidians (Barnes et al. 2006) and bivalve molluscs (e.g. cockles, D. D. Johnson pers. obs).

Whatever the processes causing the complex patterns of variation, our findings demonstrate the need for very careful planning of long-term sampling. They also emphasise the importance of pilot studies to identify important scales of temporal and spatial variation before starting a longer-term study. As discussed earlier, many studies of fish have sampled at 3-mo intervals to measure seasonal (or longer-term) changes in abundance. Evidence from our study indicates that sampling at 3-mo intervals is not an appropriate scale at which to measure seasonal change. This may well be the case (and should always be examined) in other studies of seasonal variation. For many species, variation at smaller temporal scales would confound any seasonal patterns of abundance. Demonstrating seasonal patterns requires replicate times of sampling within 3-mo periods (Morrisey et al. 1992b).

Our study also indicates strongly that, at each time of sampling, there must be replicate sites scattered across the scale of an entire estuary (i.e. separated by $1 \mathrm{~km}$ to several $\mathrm{km}$ ). Several months would probably be necessary (i.e. a whole season) to sample several sites in several different estuaries (see also Rivadeneira et al. 2002). The focus of sampling should therefore be the detection of annual, rather than seasonal, changes in abundance, which would, however, require replicate 3-mo periods to be sampled within a year (e.g. James et al. 2008).

The problem remains, however, that data are still potentially confounded when different spatial scales (e.g. sites or estuaries) are sampled on different nights or in different weeks or months within a 3-mo period. Although variation among nights may have confounded variation among sites in our study because each site was sampled on a different night, temporal variation at scales ranging from weeks to months within a 3-mo period was small compared to spatial 
variation. Thus, in future studies, providing that sites and estuaries are sampled within a 3-mo period, interpreting differences between sites (or estuaries) as probably representing spatial rather than temporal variation would probably be safe. This will not always, nor necessarily, be true for all species of fish in the estuary or in other estuaries or for periods of time longer than 6 mo.

Nevertheless, our approach represents a means to improve studies of fish and other organisms, in which the potential for short-term temporal variation to confound longer-term and larger-scale patterns, has often been ignored. Unless more attention is paid to measuring patterns of abundance at appropriate temporal and spatial scales, attempts to detect environmental impacts or to identify relevant ecological patterns and processes are likely to be compromised, inefficient, or both. Addressing these problems is necessary in designing reliable sampling procedures for any organism.

Acknowledgements. This work is part of collaborative study between Industry and Investment NSW, the Centre for Research on Ecological Impacts of Coastal Cities at the University of Sydney, and the Australian Fisheries Research and Development Corporation (Project 2002/059). Sampling was done under NSW Agriculture Animal Care and Ethics approval 02/15 and this publication conforms to the EICC's Policies on Ethics in Research. We thank D. Young, P. Lokys, J. McLeod and B. Kendall for assistance with sampling, and S. Kennelly, A. Smoothey and the anonymous referees for their comments that helped improve the paper.

\section{LITERATURE CITED}

Åberg P, Pavia H (1997) Temporal and multiple scale spatial variation in juvenile and adult abundance of the brown alga Ascophyllum nodosum. Mar Ecol Prog Ser 158:111-119

Anderson MJ (2001) A new method for non-parametric multivariate analysis of variance. Austral Ecol 26:32-46

Anderson MJ, Millar RB (2004) Spatial variation and effects of habitat on temperate reef fish assemblages in northeastern New Zealand. J Exp Mar Biol Ecol 305:191-221

Anderson MJ, Connell SD, Gillanders BM, Diebel CE, Blom WM, Saunders JE, Landers TJ (2005) Relationships between taxonomic resolution and spatial scales of multivariate variation. J Anim Ecol 74:636-646

Andrew NL, Mapstone BD (1987) Sampling and the description of spatial pattern in marine ecology. Oceanogr Mar Biol Annu Rev 25:39-90

> Auster PJ, Malatesta RJ, LaRosa SC (1995) Patterns of microhabitat utilization by mobile megafauna on the southern New England (USA) continental shelf and slope. Mar Ecol Prog Ser 127:77-85

Barnes PB, Davis AR, Roberts DE (2006) Sampling patchily distributed taxa: a case study using cost-benefit analyses for sponges and ascidians in coastal lakes of New South Wales, Australia. Mar Ecol Prog Ser 319:55-64

> Benedetti-Cecchi L (2001) Variability in abundance of algae and invertebrates at different spatial scales on rocky sea shores. Mar Ecol Prog Ser 215:79-92

Benedetti-Cecchi L (2003) The importance of the variance around the mean effect size of ecological processes. Ecology 84:2335-2346

Blaber SJM, Blaber TG (1980) Factors affecting the distribution of juvenile estuarine and inshore fish. J Fish Biol 17:143-162

Botkin DB (1990) Discordant harmonies: a new ecology for the twenty-first century. Oxford University Press, Oxford

Chapman MG, Underwood AJ (1994) Dispersal of the intertidal snail, Nodilittorina pyramidalis, in response to the topographic complexity of the substratum. J Exp Mar Biol Ecol 179:145-169

Chapman MG, Tolhurst TJ, Murphy RJ, Underwood AJ (2010) Complex and inconsistent patterns of variation in benthos, micro-algae and sediment over multiple spatial scales. Mar Ecol Prog Ser 398:33-47

Connell JH (1975) Some mechanisms producing structure in natural communities: a model and evidence from field experiments. In: Cody MS, Diamond JM (eds) Ecology and evolution of communities. Harvard University Press, Cambridge, MA, p 460-490

Creese RG, Glasby TM, West G, Gallen C (2009) Mapping the habitats of NSW estuaries. Industry and Investment NSW Fisheries Final Report Ser No. 113, Port Stephens, NSW

Cummins SP, Roberts DE, Zimmerman KD (2004) Effects of the green macroalga Enteromorpha intestinalis on macrobenthic and seagrass assemblages in a shallow coastal estuary. Mar Ecol Prog Ser 266:77-87

> Dale VH, Beyeler SC (2001) Challenges in the development and use of ecological indicators. Ecol Indic 1:3-10

> Desmond JS, Deutschman DH, Zedler JB (2002) Spatial and temporal variation in estuarine fish and invertebrate assemblages: analysis of an eleven-year data set. Estuaries 25:552-569

- Eggold BT, Motta PJ (1992) Ontogenic dietary shifts and morphological correlates in striped mullet, Mugil cephalus. Environ Biol Fishes 34:139-158

> Ellingsen KE, Gray JS (2002) Spatial patterns of benthic diversity: Is there a latitudinal gradient along the Norwegian continental shelf? J Anim Ecol 71:373-389

Ferrell DJ, Bell JD (1991) Differences among assemblages of fish associated with Zostera capricorni and bare sand over a large spatial scale. Mar Ecol Prog Ser 72:15-24

> Ferrell DJ, McNeill SE, Worthington DG, Bell JD (1993) Temporal and spatial variation in the abundance of fish associated with the seagrass Posidonia australis in south-eastern Australia. Aust J Mar Freshw Res 44:881-899

Fletcher DJ, Underwood AJ (2002) How to cope with negative estimates of components of variance in ecological field studies. J Exp Mar Biol Ecol 273:89-95

> Fraschetti S, Terlizzi A, Benedetti-Cecchi L (2005) Patterns of distribution of marine assemblages from rocky shores: evidence of relevant scales of variation. Mar Ecol Prog Ser 296:13-29

- Fraschetti S, Bianchi CN, Terlizzi A, Fanelli G, Morri C, Boero F (2001) Spatial variability and human disturbance in shallow subtidal hard substrate assemblages: a regional approach. Mar Ecol Prog Ser 212:1-12

Gibson RN, Robb L, Burrows MT, Ansell AD (1996) Tidal, diel and longer term changes in the distribution of fishes on a Scottish sandy beach. Mar Ecol Prog Ser 130:1-17

> Goodsell PJ, Underwood AJ, Chapman MG (2009) Evidence necessary for taxa to be reliable indicators of environmental conditions or impacts. Mar Pollut Bull 58:323-331

> Gray CA, McElligott DJ, Chick RC (1996) Intra- and interestuary differences in assemblages of fishes associated with shallow seagrass and bare sand. Mar Freshw Res 47:723-735 
Gray CA, Rotherham D, Chapman MG, Underwood AJ, Johnson DD (2009) Spatial scales of variation of assemblages of fish in coastal lakes sampled with multi-mesh gillnets: implications for designing research surveys. Fish Res 96: 58-63

Green RH (1979) Sampling design and statistical methods for environmental biologists. Wiley-Interscience, Chichester

Hagan SM, Able KW (2003) Seasonal changes of the pelagic fish assemblage in a temperate estuary. Estuar Coast Shelf Sci 56:15-29

Hewitt JE, Legendre P, McArdle BH, Thrush SF, Bellehumeur C, Lawrie SM (1997) Identifying relationships between adult and juvenile bivalves at different spatial scales. J Exp Mar Biol Ecol 216:77-98

Hill AS, Hawkins SJ (1991) Seasonal and spatial variation of epilithic microalgal distribution and abundance and its ingestion by Patella vulgata on a moderately exposed rocky shore. J Mar Biol Assoc UK 71:403-423

Horinouchi M (2007) Review of the effects of within-patch scale structural complexity on seagrass fishes. J Exp Mar Biol Ecol 350:111-129

Horn MH (1980) Diel and seasonal variation in abundance and diversity of shallow-water fish populations in Morro Bay, California. Fish Bull 78:759-770

> Humphries P, Potter IC (1993) Relationship between the habitat and diet of three species of atherinids and three species of gobies in a temperate Australian estuary. Mar Biol 116: 193-204

- Hurlbert SH (1984) Pseudoreplication and the design of ecological field experiments. Ecol Monogr 54:187-211

Hyndes GA, Platell ME, Potter IC, Lenanton RCJ (1999) Does the composition of the demersal fish assemblages in temperate coastal waters change with depth and undergo consistent seasonal changes? Mar Biol 134:335-352

Hyndes GA, Kendrick AJ, MacArthur LD, Stewart E (2003) Differences in the species- and size-composition of fish assemblages in three distinct seagrass habitats with differing plant and meadow structure. Mar Biol 142:1195-1206

> Ikejima K, Tongnunui P, Medej T, Taniuchi T (2003) Juvenile and small fishes in a mangrove estuary in Trang province, Thailand: seasonal and habitat differences. Estuar Coast Shelf Sci 56:447-457

> James NC, Whitfield AK, Cowley PD (2008) Long-term stability of the fish assemblages in a warm-temperate South African estuary. Estuar Coast Shelf Sci 76:723-738

> Jernakoff P (1985) The effect of overgrowth by algae on the survival of the intertidal barnacle Tesseropora rosea Krauss. J Exp Mar Biol Ecol 94:89-97

Jones MV, West RJ (2005) Spatial and temporal variability of seagrass fishes in intermittently closed and open coastal lakes in southeastern Australia. Estuar Coast Shelf Sci 64: 277-288

Katselis G, Koukou K, Dimitriou E, Koutsikopoulos C (2007) Short-term seaward fish migration in the MessolonghiEtoliko lagoons (Western Greek coast) in relation to climatic variables and the lunar cycle. Estuar Coast Shelf Sci 73:571-582

Kennelly SJ, Underwood AJ (1992) Fluctuations in the distributions and abundances of species in sublittoral kelp forests in New South Wales. Aust J Ecol 17:367-382

Krumme U, Brenner M, Saint-Paul U (2008) Spring-neap cycle as a major driver of temporal variations in feeding of intertidal fishes: evidence from the sea catfish Sciades herzbergii (Ariidae) of equatorial west Atlantic mangrove creeks. J Exp Mar Biol Ecol 367:91-99

> Levin SA (1992) The problem of pattern and scale in ecology. Ecology 73:1943-1967
Lively CM, Raimondi PT, Delph LF (1993) Intertidal community structure: space-time interactions in the northern Gulf of California. Ecology 74:162-173

> Lowry M, Williams D, Metti Y (2007) Lunar landings-relationship between lunar phase and catch rates for an Australian gamefish-tournament fishery. Fish Res 88:15-23

- McClanahan TR, Graham NAJ, Maina J, Chabanet $\mathrm{P}$, Bruggemann JH, Polunin NVC (2007) Influence of instantaneous variation on estimates of coral reef fish populations and communities. Mar Ecol Prog Ser 340: 221-234

McQuaid C, Lawrie S (2005) Supply-side ecology of the brown mussel, Perna perna: an investigation of spatial and temporal variation in, and coupling between, gamete release and larval supply. Mar Biol 147:955-963

Miller SJ, Skilleter GA (2006) Temporal variation in habitat use by nekton in a subtropical estuarine system. J Exp Mar Biol Ecol 337:82-95

Moore TN, Fairweather PG (2006) Lack of significant change in epiphyte biomass with increasing extent of measurement within seagrass meadows. Estuar Coast Shelf Sci 68: 413-420

Morrisey DJ, Howitt L, Underwood AJ, Stark JS (1992a) Spatial variation in soft-sediment benthos. Mar Ecol Prog Ser 81:197-204

Morrisey DJ, Underwood AJ, Howitt L, Stark JS (1992b) Temporal variation in soft-sediment benthos. J Exp Mar Biol Ecol 164:233-245

Morrison MA, Francis MP, Hartill BW, Parkinson DM (2002) Diurnal and tidal variation in the abundance of the fish fauna of a temperate tidal mudflat. Estuar Coast Shelf Sci 54:793-807

Olabarria C, Chapman MG (2002) Inconsistency in short-term temporal variability of microgastropods within and between two different intertidal habitats. J Exp Mar Biol Ecol 269:85-100

> Osenberg CW, Schmitt RJ, Holbrook SJ, Abusaba KE, Flegal AR (1994) Detection of environmental impacts: natural variability, effect size, and power analysis. Ecol Appl 4: $16-30$

> Platell ME, Orr PA, Potter IC (2006) Inter- and intraspecific partitioning of food resources by six large and abundant fish species in a seasonally open estuary. J Fish Biol 69: 243-262

> Pollard DA (1994) A comparison of fish assemblages and fisheries in intermittently open and permanently open coastal lagoons on the south coast of New South Wales, SouthEastern Australia. Estuaries 17:631-646

Potter IC, Claridge PN, Warwick RM (1986) Consistency of seasonal changes in an estuarine fish assemblage. Mar Ecol Prog Ser 32:217-228

> Potter IC, Beckley LE, Whitfield AK, Lenanton RCJ (1990) Comparisons between the roles played by estuaries in the life-cycles of fishes in temperate Western Australia and Southern Africa. Environ Biol Fishes 28:143-178

Rivadeneira MM, Fernández M, Navarrete SA (2002) Latitudinal trends of species diversity in rocky intertidal herbivore assemblages: spatial scale and the relationship between local and regional species richness. Mar Ecol Prog Ser 245:123-131

> Rotherham D, Gray CA, Broadhurst MK, Johnson DD, Barnes LA, Jones MV (2006) Sampling estuarine fish using multimesh gill nets: effects of panel length and soak and setting times. J Exp Mar Biol Ecol 331:226-239

Roy PS, Williams RJ, Jones AR, Yassini I and others (2001) Structure and function of south-east Australian estuaries. Estuar Coast Shelf Sci 53:351-384 
Schroeter SC, Dixon JD, Kastendiek J, Smith RO (1993) Detecting the ecological effects of environmental impacts: a case-study of kelp forest invertebrates. Ecol Appl 3: $331-350$

Steele JH (1985) A comparison of terrestrial and marine ecological systems. Nature 313:355-358

Stewart-Oaten A, Murdoch WW, Parker KR (1986) Environmental impact assessment: 'pseudoreplication' in time? Ecology 67:929-940

Thompson AA, Mapstone BD (2002) Intra- versus inter-annual variation in counts of reef fishes and interpretations of long-term monitoring studies. Mar Ecol Prog Ser 232: 247-257

Thrush SF (1991) Spatial patterns in soft-bottom communities. Trends Ecol Evol 6:75-79

Thrush SF, Pridmore RD, Hewitt JE (1994) Impacts on softsediment macrofauna: the effects of spatial variation on temporal trends. Ecol Appl 4:31-41

Thrush SF, Hewitt JE, Pridmore RD, Cummings VJ (1996) Adult/juvenile interactions of infaunal bivalves: contrasting outcomes in different habitats. Mar Ecol Prog Ser 132: 83-92

> Thrush SF, Schultz D, Hewitt JE, Talley D (2002) Habitat structure in soft-sediment environments and abundance of juvenile snapper Pagrus auratus. Mar Ecol Prog Ser 245:273-280

Underwood AJ (1984a) Vertical and seasonal patterns in competition for microalgae between intertidal gastropods. Oecologia 64:211-222

Underwood AJ (1984b) Microalgal food and the growth of the intertidal gastropods Nerita atramentosa Reeve and Bembicium nanum (Lamarck) at four heights on a shore. J Exp Mar Biol Ecol 79:277-291

Underwood AJ (1991) Beyond BACI: experimental designs for detecting human environmental impacts on temporal vari-

Editorial responsibility: Lisandro Benedetti-Cecchi, Pisa, Italy ations in natural populations. Aust J Mar Freshw Res 42: 569-587

Underwood AJ (1994) Spatial and temporal problems of monitoring. In: Calow P, Petts GE (eds) The rivers handbook: hydrological and ecological principles, Vol 2. Blackwell Scientific, London, p 101-123

Underwood AJ (1997) Experiments in ecology: their logical design and interpretation using analysis of variance. Cambridge University Press, Cambridge

Underwood AJ (1999) Physical disturbances and their direct effect on an indirect effect: responses of an intertidal assemblage to a severe storm. J Exp Mar Biol Ecol 232: 125-140

Underwood AJ, Chapman MG (1996) Scales of spatial patterns of distribution of intertidal invertebrates. Oecologia 107:212-224

Underwood AJ, Chapman MG (1998) Spatial analyses of intertidal assemblages on sheltered rocky shores. Aust J Ecol 23:138-157

Underwood AJ, Chapman MG, Connell SD (2000) Observations in ecology: You can't make progress on processes without understanding the patterns. J Exp Mar Biol Ecol 250:97-115

Walters C, Maguire J (1996) Lessons for stock assessment from the northern cod collapse. Rev Fish Biol Fish 6:125-137

West RJ, Thorogood CA, Walford TR, Williams RJ (1985) An estuarine inventory for New South Wales. Division of Fisheries, Department of Agriculture New South Wales, Sydney

Wiens JA (1989) Spatial scaling in ecology. Funct Ecol 3: 385-397

- Williams GA (1993) Seasonal variation in algal species richness and abundance in the presence of molluscan herbivores on a tropical rocky shore. J Exp Mar Biol Ecol 167: 261-275

Submitted: August 16, 2010; Accepted: May 6, 2011

Proofs received from author(s): August 12, 2011 